\title{
ANALISA DAN PERANCANGAN GAME EDUKASI KEBERSIHAN MULUT PADA ANAK UMUR 5-10 TAHUN BERBASIS ANDROID
}

\author{
Edvin Batuwael. ${ }^{(1)}$, Arie S.M Lumenta, ST. MT. ${ }^{(2)}$, Virginia Tulenan, SKom. MTI. ${ }^{(3)}$ \\ Informatics Engineering, Sam Ratulangi University, Manado, Indonesia. \\ E-mail: edvinbatuwael@gmail.com, al@unsrat.ac.id, virginia.tulenan@gmail.com
}

\begin{abstract}
Skripsi ini berisi tentang proses pembuatan game edukasi kebersihan mulut berbasis android, dengan nama game Zinc Citrate yang merupakan aplikasi game bergenre action dengan perspektif Third Person Shooter yang menceritakan tentang keadaan mulut anak yang kurang bersih sehingga munculah beberapa kuman di dalam mulut dan pemain akan mengendalikan karakter hero yang bernama Zat Zinc Citrate untuk membasmi kuman yang ada dalam mulut. Game ini bertujuan untuk memperkenalkan kepada anak-anak bahwa pentingnya menjaga kebersihan mulut. Metodologi yang digunakan untuk pembuatan aplikasi game ini adalah Extreme Programming yang meliputi empat kegiatan kerangka kerja yaitu perencanaan, perancangan, pengkodean, dan pengujian. Dengan adanya aplikasi game ini anak-anak bisa bermain sekaligus mengetahui pentingnya menjaga kesehatan mulut, diharapkan aplikasi game ini selanjutnya bisa dikembangkan tingkat kesulitannya dan dapat menggunakan database untuk menyimpan score.
\end{abstract}

\section{Kata Kunci: Game Edukasi, Extreme Programming, Android}

\section{PENDAHULUAN}

Sejak dahulu game (Permainan) sudah merupakan sebuah aktifitas rekreasi dengan tujuan bersenang-senang, mengisi waktu luang, atau berolahraga ringan. Tapi sekarang ini kita lebih mengenal yang namanya Video Game. Video Game adalah game yang berbasis elektronik dan visual, video game dimainkan dengan menggunakan media visual elektronik. Dengan perkembangan teknologi yang begitu pesat maka dunia video game pun ikut berkembang dengan cukup cepat.

Karena banyaknya peminat game maka muncul berbagai developer dibidang game, kebanyakan game yang mereka hasilkan untuk platform android, karena platform android cukup diminati masyarakat umum.

Android merupakan OS open source yang menjadi saingan $i O S$, karena $O S$ android sudah banyak digunakan pada gadget yang dapat dijangkau kalangan menengah ke bawah yang membuat android semakin terkenal dan diminati.

Menurut Developereeconomics.com ${ }^{1}$, aplikasi game sudah digunakan di $65 \%$ dari seluruh pengguna smartphone, itu berarti sekitar 40 juta orang saat ini bermain game menggunakan smartphone mereka. Itu membuat game mobile dapat menjadi bisnis yang menguntungkan.

Game juga bisa menjadi media pembelajaran alternative (Game Edukasi) dengan harapan efektif untuk diterapkan. Menurut Maria Virvou' ${ }^{9}$ dengan teknologi game dapat digunakan untuk membuat perangkat lunak sebagai media pembelajaran yang lebih memotivasi dan menarik, sehingga proses pembelajaran lebih menyenangkan. Diisi lain bahwa bermain game merupakan aktivitas yang tidak masing lagi bagi sebagaian besar anak. Bahkan tidak sedikit anak-anak yang bermain game merupakan sebuah hobby.
Sekarang ini juga kebanyakan anak-anak masih belum menyadari akan kebersihan mulut mereka, Menurut Chrisdwianto Sutjipto ${ }^{2}$ masih kurangnya kesadaran pada anak usia 6-12 tahun dalam memelihara kesehatan mulut tanpa dukungan orang tua, jika mereka tidak menjaga kesehatan mulut mereka dampaknya bisa sangat merugikan, karena gigi dan mulut merupakan komponen penting kesehatan.

Game Edukasi yang akan di buat mengambil tema kesehatan, yaitu pengenalan bahaya kuman di dalam mulut bagi anak usia 5-10 tahun dengan genre action dengan perspektif TPS (Third Person Shooter) dan diberi unsur edukasi. Desain game akan dibuat sederhana dan mengambil latar dalam mulut agar anak-anak tertarik untuk memainkan game dan mengerti makna atau pesan dari game tersebut. Background game akan menampilkan gambar kondisi di dalam mulut, memiliki beberapa karakter kuman sebagai musuh, dan karakter enzim pelindung mulut sebagai karakter pelindung mulut.

Di harapkan game ini dapat memperkenalkan anakanak bahwa pentingnya menjaga kesehatan mulut.

\section{LANDASAN TEORI}

\section{A. Game Edukasi}

Adams ${ }^{5}$ menjelaskan game adalah jenis aktivitas bermain, yang berlaku seperti berada dalam konteks sesuai kenyataan, di manapara pemain mencoba untuk mencapai setidaknya satu kewenangan, tujuan yang tidak mudah yang dilakukan sesuai dengan peraturan yang ada.

Game yang memiliki konten pendidikan lebih dikenal dengan istilah game edukasi. Game berjenis edukasi ini bertujuan untuk memancing minat belajar peserta didik terhadap materi pelajaran secara menyenangkan, sehingga dengan perasaan senang inilah yang diharapkan mereka dapat lebih mudah memahami materi pelajaran yang disajikan.

\section{Ekstreme Programming (XP)}

Pressman $^{13}$. Pemrograman Ekstrem menggunakan suatu pendekatan 'berorientasi objek' sebagai paradigm pengembangan yang diinginkan dan mencakup di dalamnya seperangkat aturan dan praktik-praktik yang terjadi dalam konteks empat kegiatan kerangka kerja: perencanaan, perancangan, pengkodean, dan pengujian. Masing-masing konteks dari ekstreme programming digunakan sebagai pendorong untuk kegiatan, tindakan, dan tugas $X P$ yang spesifik. Untuk membangun fitur-fitur dan fungsi-fungsi tertentu yang dibutuhkan perangkat lunak maka harus mencapai komunikasi yang efektif antra rekayasawan perangkat lunak dan para stakeholder. 


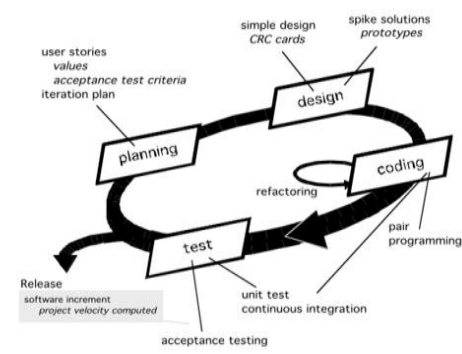

Gambar 1. Ekstreme Programming (Pressman 2010)

\section{D. $\quad U M L$ (Unified Modeling Language)}

Menurut Pressman ${ }^{13}$ UML (Unified Modeling Language) adalah bahasa standard untuk pembutan sebuah cetak biru untuk membangun sebuah aplikasi, UML berguna untuk memvisualisasikan, menentukan, mengonstruksi, dan mendokumentasikan artifakartifak suatu system.

\section{E. Pengujian Kotak Hitam (Black box Testing)}

Pengujian Kotak Hitam atau Black Box Testing biasa juga di sebut sebagai pengujian prilaku karena berfokus pada persyaratan fungsional perangkat lunak. Teknik pengujian kotak hitam memungkinkan anda untuk membuat beberapa kemungkinan kondisi masukan yang sepenuhnya akan melakukan semua kebutuhan fungsional untuk program dan bukan merupakan teknik alternatif untuk kotak putih, sebaliknya ini merupakan pendekatan pelengkap yang mungkin dilakukan untuk mengungkap kelas kesalahan yang berbeda dari yang diungkapkan oleh metode kotak putih. Pengujian kotak hitam bertujuan untuk menemukan kesalahan dalam kategori berikut: (1) fungsi yang salah atau hilang, (2) Kesalahan antarmuka, (3) kesalahan dalam struktur data atau akses basis data eksternal, (4) kesalahan prilaku atau kinerja, dan (5) keselahan inisialisasi dan penghentian.

\section{METODE PENELITIAN}

\section{A. Kerangka Kerja}

Berikut adalah kerangka kerja yang akan menggambarkan tahapan pengerjan aplikasi.

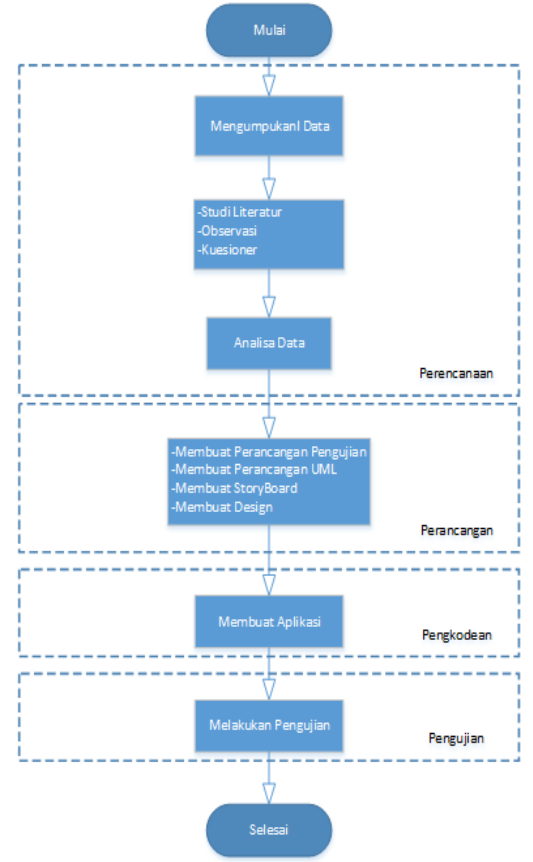

Gambar 2. Kerangka Kerja.

\section{B. Metodologi}

Pada pembuatan game ini digunakan metode perancangan Extreme Programming $(X P)$ dengan tahapan sebagai berikut.

\section{Perencanaan}

Pada tahap perencanaan dilakukan pengumpulan data untuk pembuatan game, pengumpulan data dilakukan dengan cara studi lteratur, dan observasi untuk mendapatkan data yang di perlukan untuk pembuatan game.

\section{Perancangan}

Pada tahap perancangan dilakukan perancangan $U M L$, perancangan story board, dan merancang karakter game, background game, tampilan UI game.

\section{Pengkodean}

Pada tahapan ini dilakukan pengkodean untuk menjalankan fungsi aplikasi sesuai dengan rancangan yang telah dibuat.

\section{Pengujian}

Pada tahapan ini dilakukan pengujian sesuai dengan perencanaan proses testing yang telah disiapkan pada tahap perancangan. Tujuannya agar memastikan fitur-fitur dan fungsi-fungsi yang ada pada game sudah tercapai atau beleum, jika belum akan dilakukan refactory.

\section{Analisa User}

Dari hasil analisis user lewat kuisioner diketahui anak laki-laki merupakan jumlah terbanyak dalam pengisian kuesioner dengan kiasran umur terbanyak 5-6. Dari hasil analisis user ini diketahui anak-anak sering menyikat gigi sebanyak 2x sehari, tapi tidak menyikat gigi sebelum tidur, anak-anak juga menyikat gigi dikarenakan disuruh orang tua dan anak-anak masih belum tahu pentingnya menjaga kebersihan mulut.

\section{Perancangan}

Pada tahap perancangan ini mulai dilakukan perancangan $U M L$, perancangan story board, dan merancang karakter game, background game, tampilan UI game.

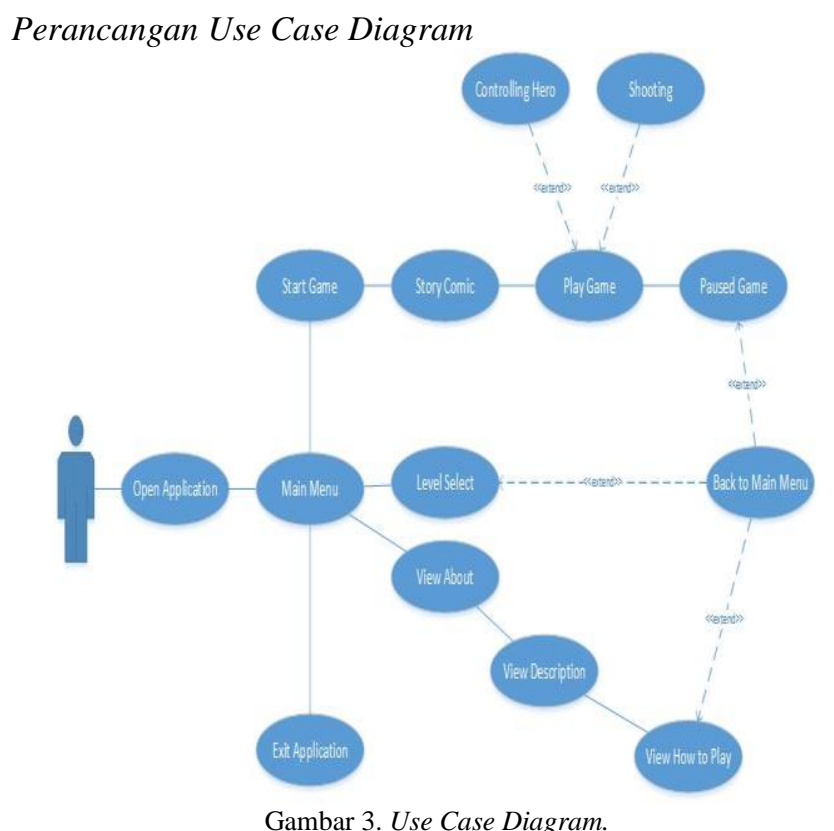




\section{Perancangan Story Board}

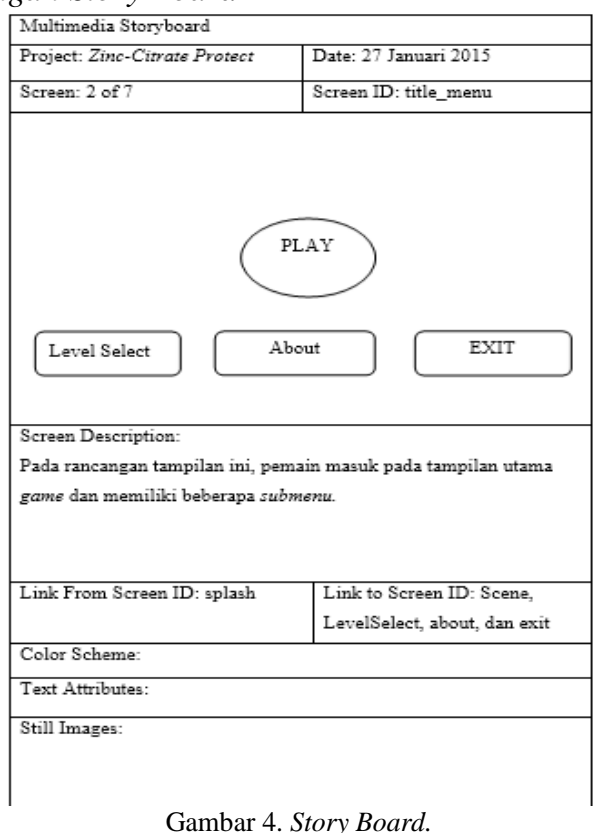

Perancangan Karakter

Gambar 4. Story Board.

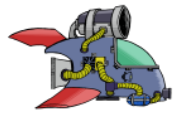

Gambar 5. Karakter Hero Zinc Citrate.

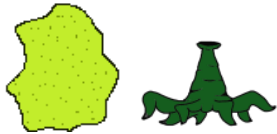

Gambar 6. Karakter Enemy. Kuman.

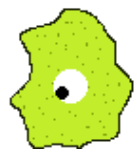

Gambar 7. Karakter Enemy.Bos Kuman.

Perancangan Background

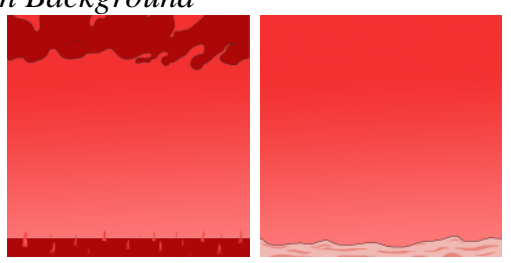

Gambar 8. Background.

Perancangan Cover Game

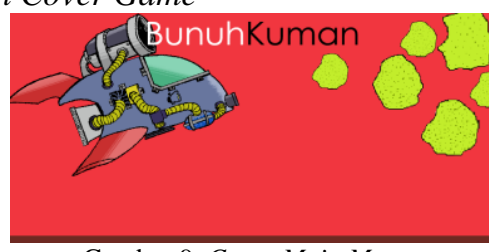

Gambar 9. Cover Main Menu.

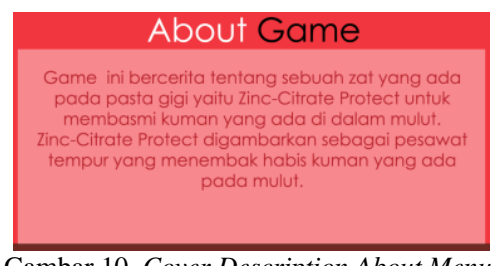

Gambar 10. Cover Description About Menu.
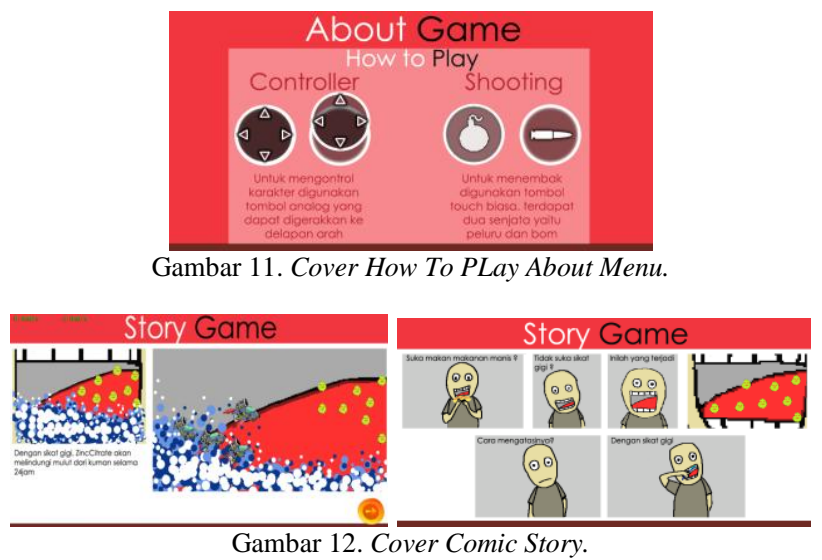

Perancangan Button

D. Pengkodean

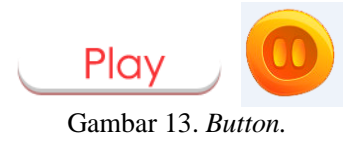

Setelah selesai melakukan perancangan interface game dan karakter game maka di lanjutkan ke tahap pengkodean.

\section{Pengkodean Background}

Pada background terdiri dari 3 buah gambar dan akan dibuat bergerak secara berulang (Looping) menggunakan script ScroolingScript.cs. Kamera akan menampilkan gambar pertama, kedua, ketiga, saat gambar ke tiga maka kamera akan menampilkan kembali ke gambar pertama. Pengulangan gambar ini akan membuat latar menjadi terlihat bergerak, seperti yang terlihat pada gambar 14 .

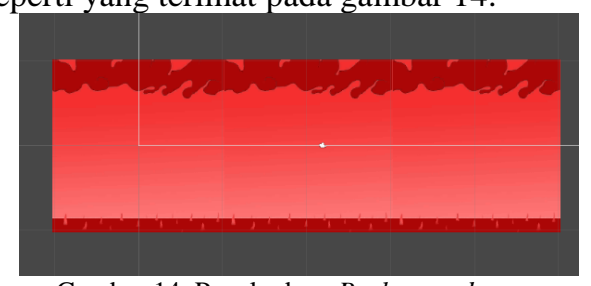

Gambar 14. Pengkodean Background.

\section{Pengkodean Karakter Hero}

Pada gambar 15 ini merupakan tampilan karakter hero setelah di beri script, agar Karakter hero ini bisa dikendalikan maka diberi script PlayermovementGO.cs. Pada script ini terdapat perintah yang akan menggerakkan karakter hero ke atas atau kebawah dengan nilai Y dan kekiri atau kekanan dengan nilai X. Jika karakter ingin digerakkan ke atas maka nilai $\mathrm{Y}$ akan ditambah, jika ingin digerakkan kebawah maka nilai $\mathrm{Y}$ akan dikurang. Dan jika ingin digerakkan ke kiri maka nilai $\mathrm{X}$ akan di kurang, jika ingin digerakkan ke kanan maka nilai $\mathrm{X}$ akan ditambah. Untuk mengendalikan karakter digunakan media controller yaitu Control-Freak.

Kemudian untuk menembak digunakan script PlayerShooting.cs. Tembakan akan keluar jika pemain menekan tombol menembak dengan delay tembakan 0.25 (Bisa diubah).

Pada karakter hero juga terdapat script DemageHandler.cs. pada script ini terdapat health dari karakter hero, jika health karakter hero menjadi 0 maka script akan memanggil animation Explotion dan mengurangi nilai score.

Pada karakter hero juga diberi script MoveScript.cs, script ini akan membuat karakter hero terbang secara otomatis ke kiri dengan kecepatan $\mathrm{X}=1$ berlawanan arah 
dengan pergerakkan background, ini dimaksud agar pesawat terlihat otomatis terbang kedepan.

Dan script terakhir adalah ScroolingScriptHero.cs, script ini membuat kamera mengikuti gambar karakter sepanjang permainan berlangsung.

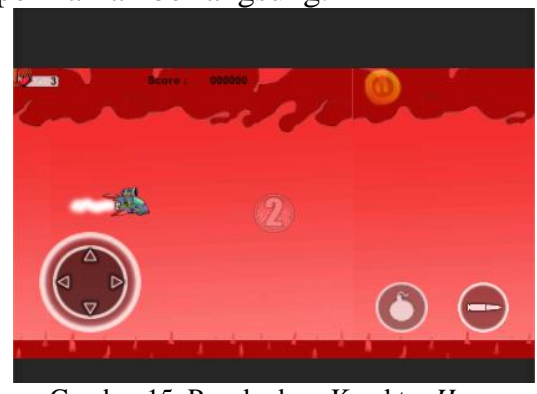

Gambar 15. Pengkodean Karakter Hero.

\section{Pengkodean Karakter Enemy}

Pada gambar 16 ini merupakan tampilan karakter enemy setelah di beri script, untuk membuat karakter enemy kuman dibuat bergerak secara otomatis, kuman akan bergerak lurus kearah kiri, script yang digunakan adalah MoveScript.cs. Script ini akan membuat karakter enemy bergerak secara otomatis kekiri dengang kecepatan $X=5$.

Kuman juga akan menembak secara sendirinya jika hero berada dijarak kurang dari 20 dengan delay tembakan bernilai 1, script yang digunakan adalah EnemyShooting.cs.

Pada karakter kuman juga terdapat script DemageHandlerEnemy.cs, pada script ini terdapat health dari karakter enemy, saat health menjadi 0 maka script akan memanggil animation splash dan memberi nilai score.

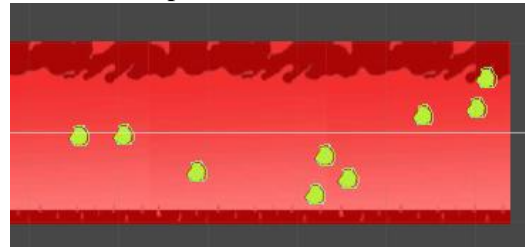

Gambar 16. Pengkodean Karakter Enemy.

Pengkodean Karakter Enemy Bos

Pada gambar 17 ini merupakan tampilan karakter enemy bos setelah di beri script, karakter enemy bos juga akan bergerak secara otomatis kearah kiri, namun akan berhenti jika bertemu dengan karakter hero dengan jarak kurang dari 20, script yang digunakan adalah bosMoveScript.cs.

Karakter ini juga akan menembak secara otomatis dari jarak kurang dari 20, script yang digunakan adalah EnemyShooting.cs.

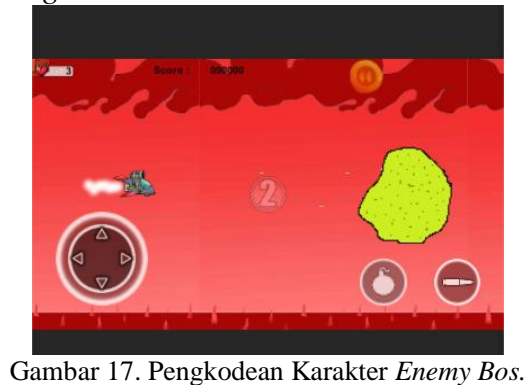

Pengkodean Splash Screen

Pada tampilan splash screen ini digunakan logo Informatika Unsrat, seperti terlihat pada gambar 18. Pada splash screen ini digunakan script SplashScreen.cs yang berfungsi memanggil scene menu utama saat gambar splash screen selesai ditampilkan.

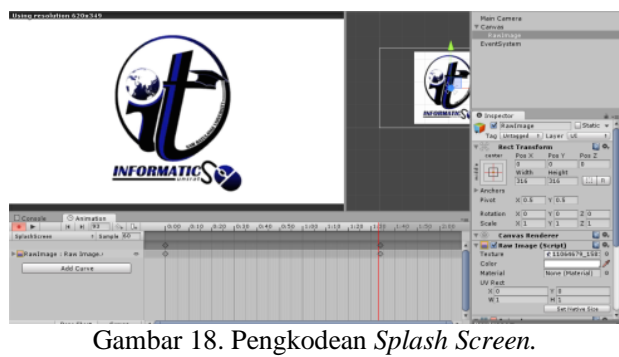

Pengkodean Scene Main Menu

Pada gambar 19 dilakukan pembuatan tampilan menu utama yang terdiri dari cover dan button yang akan memanggil scene berbeda. Selain cover dan button terdapat juga background music pada tampilan menu utama ini. Scene main menu merupakan menu pertama yang diakses oleh pemain, pada scene ini di beri script Main_menu.cs yang berfungsi untuk memanggil scene berbeda saat tombol ditekan.

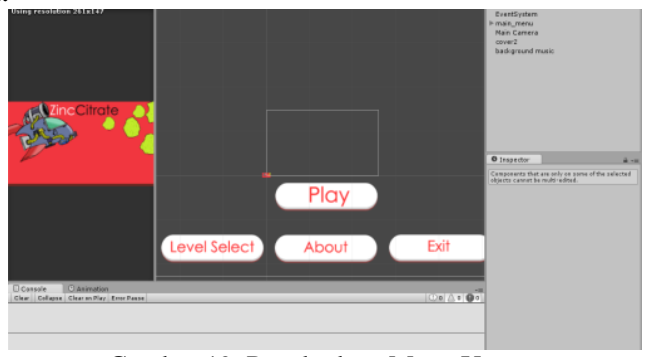

Gambar 19. Pengkodean Menu Utama.

\section{Pengkodean Scene Comic Story}

Pada gambar 20 merupakan tampilan dari comic story yang teridiri dari cover gambar, tombol next, dan background music. Pada scene comic story ini diberi script About_menu.cs untuk mengarahkan tombol untuk memanggil scene berbeda.

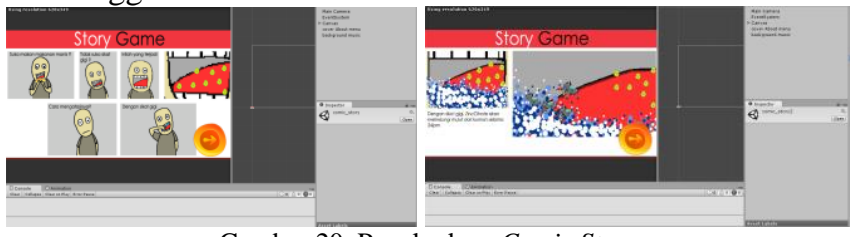

Gambar 20. Pengkodean Comic Story.

\section{Pengkodean Scene Level Select}

Gambar 21 merupakan tampilan scene level select yang terdiri dari cover, button level, button back, gambar lock dan background music. Pada scene level select terdapat script LevelSelectManager.cs yang yang berisi fungsi untuk memanggil scene berbeda saat tombol di tekan, tags untuk membuka level, dan tags untuk level yang sudah terunlock.

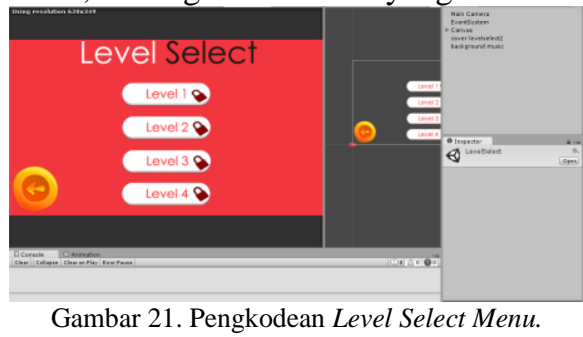

\section{Pengkodean Scene About}

Pada scene about terdapat cover dengan gambar penjelasan game, tombol back, dan tombol next, seperti gambar 22. Kemudian pada scene about yang kedua terdapat 
cover dengan gambar penjelsan cara bermain dan tombol back, seperti gambar 23. Pada scene about ini digunakan script About_menu.cs untuk memanggil scene berbeda saat tombol ditekan.
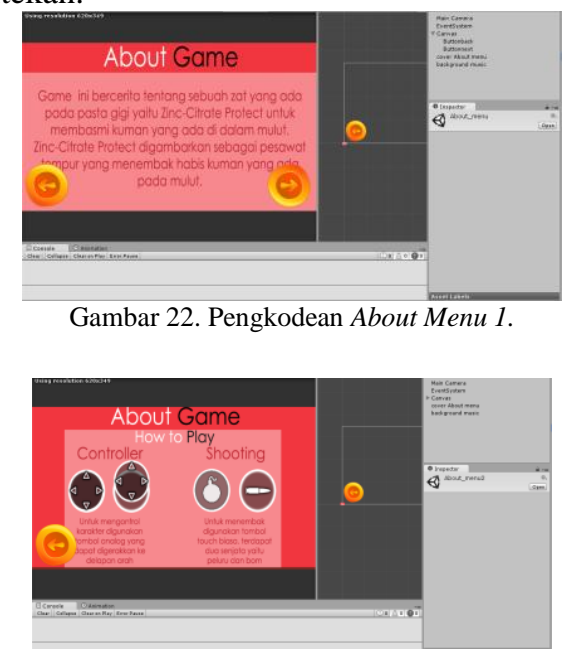

Gambar 23. Pengkodean About Menu 2.

Pengkodean Scene Game Over

Pada scene game over ini terdapat cover, tombol retry, dan tombol back to main menu, seperti terlihat pada gambar 24. Pada scene game over ini juga terdapat script gameOver.cs yang memiliki fungsi untuk memanggil scene berbeda saat tombol ditekan. Scene game over ini akan muncul jika karakter hero hancur dan sudah tidak memiliki sisa number live.

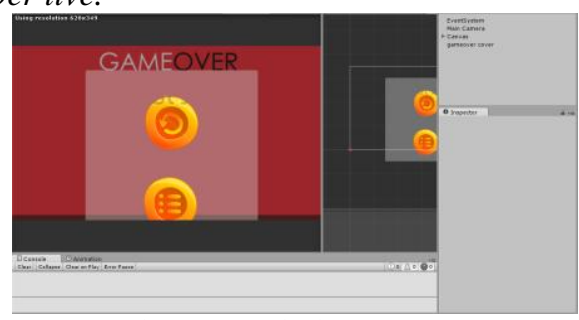

Gambar 24. Pengkodean Game Over.

\section{Pengkodean Scene Paused Menu}

Paused menu terdapat pada scene permainan dan akan muncul jika tombol paused ditekan. Pada paused menu terdapat canvas yang diberi warna hitam transparan, dan terdapat tombol continue dan back to main menu, seperti terlihat pada gambar 25. Paused menu terdapat script PauseMenu.cs yang berfungsi untuk mengaktifkan paused menu dan memanggil scene lain saat tombol ditekan.

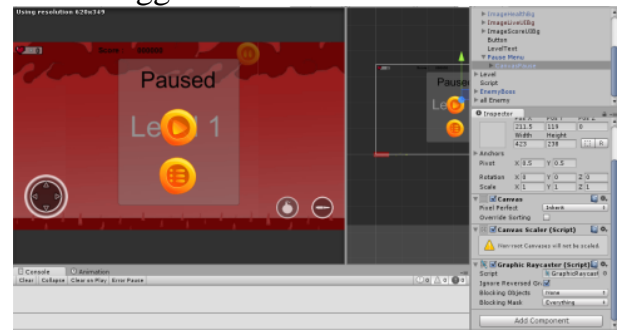

Gambar 25. Pengkodean Paused Menu.

\section{HASIL DAN PEMBAHASAN}

\section{A. Tampilan Aplikasi Game}

Berikut adalah tampilan dari aplikasi game Zinc Citrate yang dimainkan langsung dari smartphone. Terdapat tampilan icon game, splash screen, main menu, level select mеnu, about тепи, paused тепи, game over mеnu, dan scene permainan.
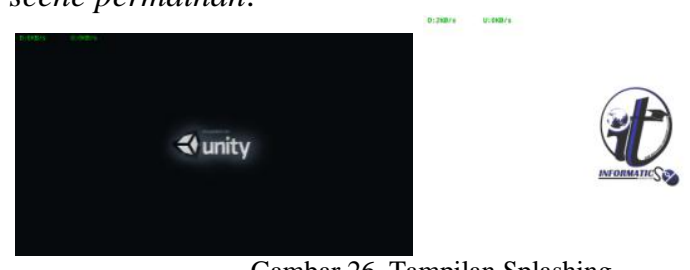

Gambar 26. Tampilan Splashing.

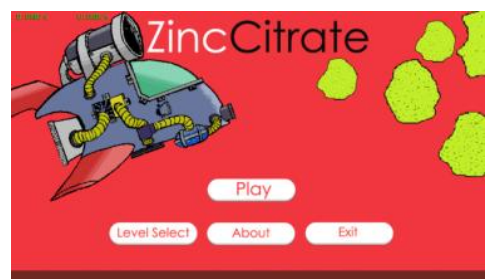

Gambar 27. Tampilan Menu Utama.

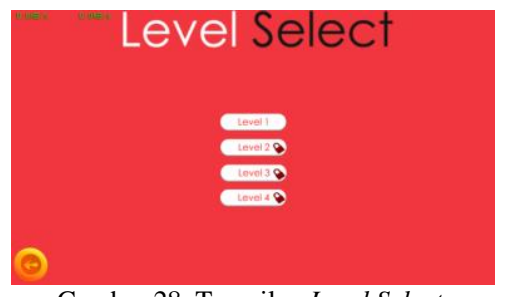

Gambar 28. Tampilan Level Select.

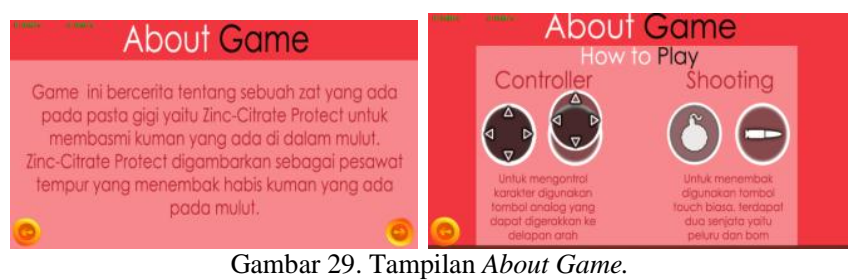

Gambar 29. Tampilan About Game.

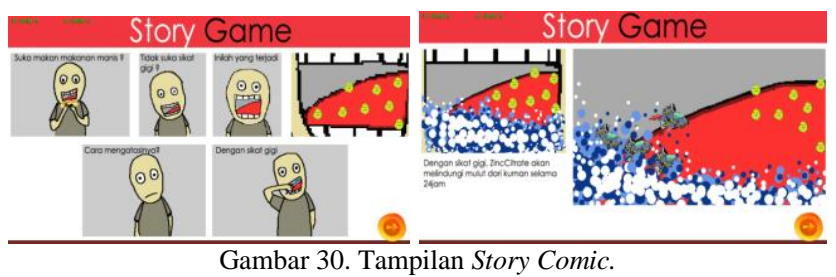

Gambar 30. Tampilan Story Comic

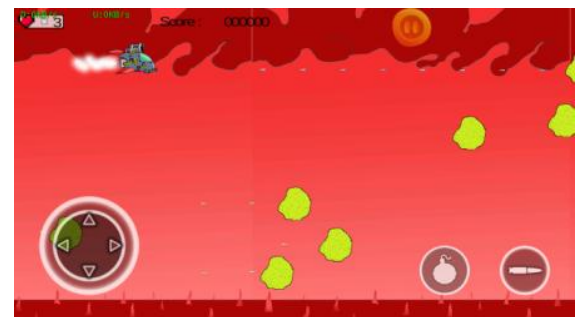

Gambar 31. Tampilan Hero Menembak.

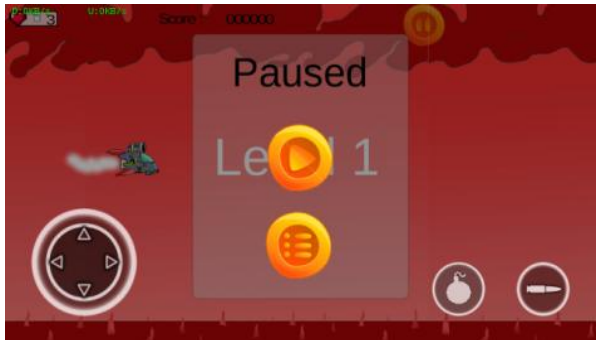

Gambar 32. Tampilan Paused Menu. 


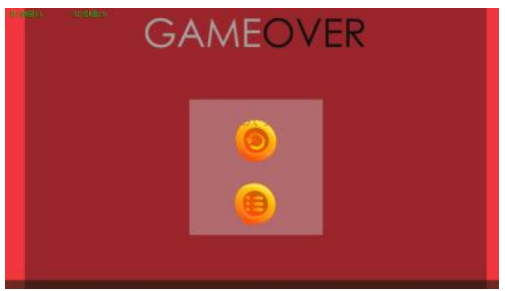

Gambar 33. Tampilan Game Over

\section{B. Pengujian}

Pada tapan ini akan dilakukan pengujian pada fungsifungsi yang ada pada game dan mengecek fitur-fitur sesuai dengan rancangan yang telah dibuat. Pengujian dilakukan terhadap beberapa feature yang sudah ditetapkan.

Tabel 1. Black Box Testing.

\begin{tabular}{|c|c|c|c|c|}
\hline Feature & Expected Result & $\begin{array}{c}\text { Met } \\
\text { Expectation }\end{array}$ & Proof & Comment \\
\hline Main Menu & $\begin{array}{c}\text { Pemain masuk ke } \\
\text { menu utama sebelum } \\
\text { permainan } \\
\text { berlangsung }\end{array}$ & Yes & Gambar 27 & $\begin{array}{l}\text { Tampilan menu } \\
\text { utama bisa } \\
\text { dikembangkan } \\
\text { selanjutnya }\end{array}$ \\
\hline Play Game & $\begin{array}{c}\text { Pemain dapat } \\
\text { memulai permainan }\end{array}$ & Yes & Gambar 31 & $\begin{array}{c}\text { Permainan dapat } \\
\text { dikembangkan sesuai } \\
\text { kebutuhan }\end{array}$ \\
\hline $\begin{array}{l}\text { Level } \\
\text { Select }\end{array}$ & $\begin{array}{l}\text { Pemain dapat } \\
\text { memilih level }\end{array}$ & Yes & Gambar 28 & $\begin{array}{l}\text { Leve/ yang ada bisa } \\
\text { ditambahkan dengan } \\
\text { tingkatan yang lebih } \\
\text { sulit dan menantang }\end{array}$ \\
\hline View About & $\begin{array}{c}\text { Pemain dapat } \\
\text { melihat penjelasan } \\
\text { sekilas tentang } \\
\text { aplikasi gome }\end{array}$ & Yes & Gambar 29 & $\begin{array}{c}\text { Tampilan about menu } \\
\text { yang berisi } \\
\text { penjelasan } \\
\text { selanjutnya bisa } \\
\text { dikembangkan lagi }\end{array}$ \\
\hline $\begin{array}{c}\text { Exit } \\
\text { Application }\end{array}$ & $\begin{array}{l}\text { Pemain dapat keluar } \\
\text { dari permainan }\end{array}$ & Yes & & - \\
\hline $\begin{array}{l}\text { Poused } \\
\text { Menu }\end{array}$ & $\begin{array}{l}\text { Pemain dapat } \\
\text { Menghentikan } \\
\text { permainan }\end{array}$ & Yes & Gambar 32 & $\begin{array}{l}\text { Tampilan menu } \\
\text { pause bisa di } \\
\text { kembangkan }\end{array}$ \\
\hline Game Over & $\begin{array}{l}\text { Pemain dapat } \\
\text { melihat } \\
\text { pemberitahuan jika } \\
\text { permainan berakhir }\end{array}$ & Yes & Gambar 33 & $\begin{array}{c}\text { Tampilan menu gome } \\
\text { over bisa } \\
\text { dikembangkan lagi. }\end{array}$ \\
\hline $\begin{array}{l}\text { Splash } \\
\text { Screen }\end{array}$ & $\begin{array}{l}\text { Pemain melihat } \\
\text { tampilan gambar } \\
\text { sekilas berisi logo } \\
\text { game }\end{array}$ & Yes & Gambar 26 & $\begin{array}{c}\text { Tampilan splash pada } \\
\text { game ini digunakan } \\
\text { logo Informatika } \\
\text { Unsrat. }\end{array}$ \\
\hline
\end{tabular}

\section{Evaluasi Pengguna}

Dari Evaluasi pengguna lewat kuisioner ke 2 setelah game edukasi diberikan kepada pengguna yaitu anak usia 510 tahun dimana anak laki-laki merupakan jumlah terbanyak dalam pengisian kuesioner dengan umur terbanyak 7 tahun, dan sebesar $99 \%$ sudah tahu pentinya akan kebersihan mulut, mereka juga mau menyikat gigi pada malam hari sebelum tidur tanpa disuruh orang tua.

\section{KESIMPULAN DAN SARAN}

\section{A. Kesimpulan}

Telah dihasilkan game edukasi kebersihan mulut bergenre action dengan perspektif TPS (Third Person Shooter) dan dengan adanya aplikasi game ini anak-anak bisa bermain sekaligus mengetahui akan pentingnya menjaga kesehatan mulut.
B. Saran

Untuk pengembangan selanjutnya bisa menggunakan database untuk menyimpan nilai score dan bisa menambah level atau tingkat kesulitan pada game hingga game bisa di mainkan di semua kalangan usia.

\section{DAFTAR PUSTAKA}

[1] Christian Voskoglou. (2013). The Multi-Platform Developer [online]. Available: http://www.developereconomics.com/report/q3-2013-the-multiplatform-developer/

[2] Chrisdwianto Sutjipto, "Gambaran Tindakan Pemeliharaan Kesehatan Gigi dan Mulut Anak Usia 10-12 Tahun Di SD Kristen Eben Haezar 02 Manado", Jurnal e-Biomedik (eBM), Volume1, Nomor 1, Maret 2013.

[3] Dave Calabrese, Unity 2D Game Development: Pack Publishing, 2014.

[4] Dony Novaliendry, “Aplikasi Game Geografi Berbasis Multimedia Interaktif: Jurnal Teknologi Informasi dan Pendidikan", Jurnal Teknologi Informasi \& Pendidikan, Volume 6, Nomor 2, September 2013.

[5] Ernest Adams, Fundamentals Of Game Design, Secon Edition: New Riders, 2010.

[6] John Sharp, Microsoft Visual C\# - Step by step, First Edition: Microsoft, 2012.

[7] John Sharp, Microsoft Visual C\# - Step by step, Secon Edition : Microsoft, 2013

[8] Kendall dan Kendall, System Analysis and Design. Edition 8: Prentice Hall, 2006

[9] Maria Virvou, "Combining Software Games with Education: Evaluation of its Educational Effectiveness", Jurnal Evaluation of its Educational Effectivess. Education technology \& Society, 8 (2), 54-65, 2005

[10]Magdalena Claro, "OECD Background Paper for OECDENCLACES Expert Meetng VIDEO GAMES AND EDUCATION", Jurnal October 2007.

[11]Rickman Roedavan, Unity Tutorial Game Engine, First Edition, Bandung: Informatika Bandung, 2014.

[12]Rick Rogers, Learning Android Game Programming. First Edition, Indiana: Wesley, 2012.

[13]Roger S. Pressman, Rekayasa Perangkat Lunak- Pendekatan Praktisi Buku 1, Edition 7, Yogyakarta :Andi, 2012.

[14]Roger S. Pressman, Rekayasa Perangkat Lunak- Pendekatan Praktisi Buku 2. Edition 7, Yogyakarta :Andi, 2012.

[15]Wei-Meng Lee, Beginning Android 4 Application Development, Fisrt Edition, Canada: Wiley, 2012.

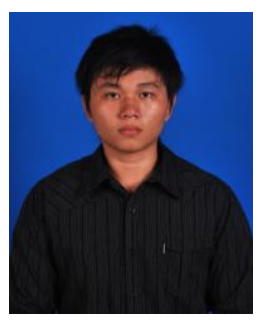

Sekilas dari penulis dengan nama lengkap Edvin Batuwael, lahir pada tanggal 22 Maret 1993 di Jikumerasa, Maluku Utara. Anak ke 2 dari 4 bersaudara. Lulusan dari SD GMIM 25 Manado pada tahun 2005, lulusan dari SMP Negeri 3 Manado pada tahun 2008 dan lulusan dari SMA Negeri 3 Manado pada tahun 2011. Setelah lulus SMA pada tahun 2011 melanjutkan ke perguruan tinggi tepatnya di Universitas Sam Ratulangi Manado dengan mengambil jurusan Teknik Informatika. Dan pada tanggal 31 November 2015 telah menyelesaikan Ujian Skripsi Program Studi Teknik Informatika Jurusan Tenik Elektro Fakultas Teknik Universitas Sam Ratulangi dan menyandang sebagai Sarjana Komputer dengan predikat sangat memuaskan. Ini semua berkat bimbingan dan arahan dari dosen pembimbing Arie S.M. Lumenta, ST., MT. dan Virginia Tulenan, Skom., MTI. 